\title{
Quality of Life of Severe Sepsis Survivors After Hospital Discharge ${ }^{1}$
}

\author{
Ligia Marcia Contrin² \\ Vania Del'Arco Paschoal ${ }^{2}$ \\ Lucia Marinilza Beccaria² \\ Claudia Bernardi Cesarino ${ }^{2}$ \\ Suzana Margareth Ajeje Lobo ${ }^{2}$
}

\begin{abstract}
Aims: to evaluate the quality of life in severe sepsis survivors, using specific QoL questionnaires: the EuroQol-5 Dimensions and the Visual Analogue Scale (EQ-VAS). Method: This case-control study was performed in patients discharged from a teaching hospital after being admitted to the ICU with severe sepsis. Medical records from 349 patients were retrieved from the hospital sepsis registry. Each patient with sepsis was considered as a case. Patients who were admitted immediately after the sepsis episode were considered as controls, provided that they did not have sepsis and survived the ICU admission. This specific study population included 100 patients. Results: The sepsis group showed higher mortality at 1 year compared with critically ill patients. However, the control group showed no sepsis. Older patients ( $>60$ years) in the sepsis group had a significantly higher prevalence of problems. There were no differences in EQ-VAS between respondents from both groups. Conclusions: After discharge from ICU, sepsis survivors of sepsis had a higher mortality rate than critically ill patients without sepsis. Older patients with sepsis had more moderate and severe problems in all five quality of life dimensions evaluated.
\end{abstract}

Descriptors: Survivors; Sepsis; Intensive Care Units; Quality of Life

\footnotetext{
${ }^{1}$ Paper extracted from Doctoral Dissertation "Qualidade de Vida em Sobreviventes de Sepse Graves Após Alta Hospitalar" presented to Faculdade de Medicina de São José do Rio Preto, São José do Rio Preto, SP, Brazil. Supported by Coordenação de Aperfeiçoamento de Pessoal de Nível Superior (CAPES), \# process 230380097962/2010-47.

2 PhD, Adjunct Professor, Faculdade de Medicina de São José do Rio Preto, São José do Rio Preto, SP, Brazil.
}

Corresponding Author:

Ligia Marcia Contrin

Av. Brigadeiro Faria Lima, 5416

Bairro: São Manoel

CEP: $15090-000$

São José do Rio Preto, SP, Brasil

E-mail: ligiacontrin@famerp.br 


\section{Introduction}

Sepsis has gained great epidemiological importance. The incidence of sepsis increased by $90 \%$ in the past decade and continues to increase by $1.5 \%$ every year(1). Despite treatment, the mortality of these patients remains extremely high, ranging from $40 \%$ to $50 \%{ }^{(2)}$. Its increasing prevalence and the emergence of new etiologies are related to changes in the demographic characteristics of the population and to the increasingly frequent use of immunosuppressive therapy and invasive procedures $^{(3-4)}$

In Brazil, approximately $25 \%$ of the patients hospitalized in intensive care units (ICUs) had severe sepsis, with mortality rates ranging from $35 \%$ to $65 \%{ }^{(4)}$. The high lethality of sepsis is not restricted to the acute phase of the disease. It also increases the risk of death over the years following hospital discharge(5). Studies have shown significant cognitive sequelae in survivors

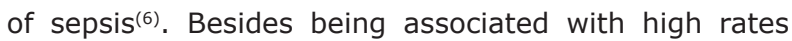
of hospital mortality, sepsis may also jeopardize the quality of life of those who survive hospitalization. It also compromises long-term survival(7).

Because of immunosuppression and possibly another reason yet not well known at the moment, patients who had sepsis in hospital are still considered as at a higher risk of death after hospital discharge. In the USA, a $37 \%$ mortality rate in ICU patients has been reported, but only $49 \%$ of patients survived the hospitalization and $72 \%$ died within a year after hospital discharge ${ }^{(3,8)}$.

Sepsis may be costing the health care system in a variety of ways, including significant loss of productivity due to the long periods of hospitalization required and high associated early and late mortality $\operatorname{rates}^{(9-10)}$.

Advances in the treatment of sepsis have reduced mortality rates. The possibilities of reintegrating these individuals in society so as to keep their social relationships, physical activity, and labor activities in a satisfactory way, however, are commonly overlooked in most studies ${ }^{(11)}$.

The concept of quality of life is subjective and, therefore, its definition is variable and difficult(12). The assessment of quality of life is based on the individual's perception of his/her health status. This perception includes domains or dimensions, which are set in his/ hers cultural context, system of values, expectations, life-style standards and concerns. Although difficult to perform, a number of tools have been proposed in an attempt to assess patients' quality of life. Some questionnaires have been developed and used to assess the patients' quality of life, focusing on various aspects and dimensions, such as the physical, psychological, social, overall performance, pain and sleep, among some others ${ }^{(13)}$

The United Nations estimates that, from 2000 to 2025 , the number of people over 65 years will increase $67 \%$ in developed countries and $44 \%$ in less developed countries. The level of health, high demand for hospital and ICU beds and quality of life after hospitalization poses great concerns, particularly in the elderly. Technological developments and concepts of economics in health have made it necessary to evaluate not only the efficacy and harm of interventions, but also their impact on individuals' quality of life ${ }^{(13)}$. The aim of this nested case-control study was to evaluate quality of life in severe sepsis survivors, based on the EuroQol-5 Dimensions (EQ-5D) and the Visual Analogue Scale (EQVAS).

\section{Materials and Methods}

Approval of data collection was obtained from the Research Ethics Committee (number: 6310/2008). The need for written informed consent was waived in view of the anonymous nature of the study. Data collection was conducted via telephone interview. The aim of the study was explained to the patients before they agreed to participate in the study. The study was carried out among patients discharged from a tertiary teaching hospital after being admitted in the ICU with severe sepsis (24-bed mixed ICU). Data were retrieved from our local registry Intensive Medicine Research Center of Study (Centro de Estudos e Pesquisa em Medicina Intensiva-CEPEMI) of patients with severe sepsis. This registry was performed by the medical residents and included patients admitted from May 2004 to December 2009, covering a minimum 1-year period after discharge. Patients were enrolled under the conditions of being 18 years of age or older, and having a clinical diagnosis of severe sepsis (i.e. two or more systemic inflammatory response syndrome (SIRS) criteria, evidence of infection, and at least one sepsis-induced organ dysfunction (OD) (14-15). Each patient with sepsis was considered as a case and the patient who was admitted immediately after was selected as a control, as long as they did not have sepsis and survived ICU admission.

In total, 349 patients' records were retrieved from the CEPEMI database and survivors were screened during the study period. The sample was divided into 
two groups: Control Group [C group] $(n=164)$ and Sepsis Group [S group] $(n=185)$. All data were retrieved from the patients' hospital database files. In the $\mathrm{S}$ group, 185 patients were evaluated and 50 (27.03\%) were included. Of these 185 patients initially enrolled in the study, $31(16.76 \%)$ died in less than one year; two (1.08\%) died after one year; 49 (26.49\%) could not be identified; two $(1.08 \%)$ refused to participate, and 51 $(27.57 \%)$ could not be located in two attempts made. In total, 164 patients were enrolled in the $C$ Group. Of the 164 patients, $14(8.54 \%)$ died in less than one year, six $(3.66 \%)$ died after one year; $11(6.71 \%)$ could not be identified; one $(0.61 \%)$ refused to participate, and 82 $(50 \%)$ could not be located (Figure 1 ).

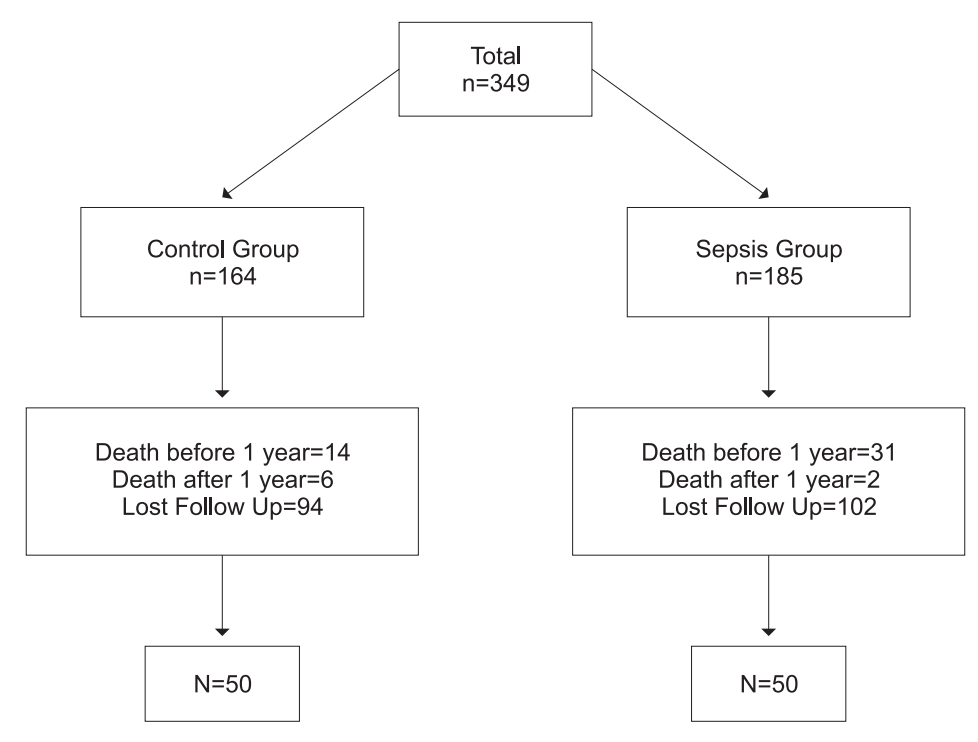

Figure 1 - Flow Chart of the study population

The primary objective of the study was to evaluate the quality of life in sepsis survivors, using the questionnaires EQ-5D and EQ-VAS, considering that these instruments can be used for data collection via telephone contact. This allows the questionnaires to be answered by the subject or his/her next of kin/legal representatives/responsible. The secondary objectives were to observe characteristics such as gender, age, educational level and socioeconomic status, hospital and ICU length of stay and mortality.

Demographic data and clinical characteristics were collected from the CEPEMI registry and the hospital medical records. Up to three attempts to contact all patients by phone were made in the morning, in the afternoon and at night if necessary. Fifty patients or their family members in each group were asked to answer a semi-structured questionnaire after explanation and clarification of the purpose of the present study. The two major components of the EQ-5D were applied(16-17). The first component defines the health-related quality of life (HR-QoL) and comprises five dimensions (mobility, self-care, usual activities, pain/discomfort, and anxiety/ depression), each one with three levels of severity ( 1 : no problems; 2: some problems; 3 : extreme problems).
The Visual Analogue Scale (VAS), the second component in a self-rated health state, uses a scale numbered from 0 (the worst imaginable state of health) to 100 (the best imaginable state of health). The EQ-5D was thereafter converted into a single summary index by applying a formula that attaches values (weights) to each of the levels defined by the five dimensions ${ }^{(17)}$. The health state indexes were obtained by deducting the relevant weights from one.

\section{Statistical Analysis}

Data are presented as medians and interquartile ranges (IQ), absolute values and percentages with 95\% confidence intervals (CI) where appropriate, or means and standard deviations (SD). Mann-Whitney's $\mathrm{U}$ test was used for comparison of continuous variables. Multiple groups were compared with the Kruskal-Wallis test. A $p<0.05$ was considered statistically significant.

\section{Results}

Demographic data, educational and socioeconomic data of both groups are shown in Table 1. Survivors' mean age at hospitalization was 52.2 in the $\mathrm{C}$ group and 
51.3 in S group. Patients with sepsis had significantly longer lengths of stay in the hospital (24.2 \pm 15.3 days) than patients in the control group (14.8 \pm 10.2 days) $(p<0,001)$ (Table1). In addition, patients with sepsis spent more days in the ICU (10.8 \pm 9.5 days) in comparison to controls ( $4.8 \pm 4.2$ days) $(p<0.001)$.

Table 1 - Demographic data and characteristics of the groups. São José do Rio Preto, SP, Brazil, 2010

\begin{tabular}{|c|c|c|}
\hline & Control Group & Sepsis Group \\
\hline $\mathrm{N}^{\circ}$ of patients & 50 & 50 \\
\hline \multicolumn{3}{|l|}{ Gender (\%) } \\
\hline Male & 48 & 64 \\
\hline Age (years) (median $\pm \mathrm{SD}$ ) & $52.2 \pm 19.4$ & $51.3 \pm 20.0$ \\
\hline \multicolumn{3}{|l|}{ Type of hospitalization, n (\%) } \\
\hline Medical & $27(54)$ & $29(58)$ \\
\hline Surgical & $23(46)$ & $21(42)$ \\
\hline \multicolumn{3}{|l|}{ Main diagnosis, $\mathrm{n}(\%)$} \\
\hline Respiratory Tract & $4(8)$ & $11(22)$ \\
\hline Urinary Tract & $3(6)$ & $5(10)$ \\
\hline Cardiovascular Tract & $3(6)$ & $4(8)$ \\
\hline Nervous system & $9(18)$ & $5(10)$ \\
\hline Trauma & $6(12)$ & $10(20)$ \\
\hline Gastrointestinal Tract & $12(24)$ & $4(8)$ \\
\hline Tumor & $10(20)$ & $4(8)$ \\
\hline Sepsis & $2(4)$ & $1(2)$ \\
\hline Metabolic Diseases & $0(0)$ & $2(4)$ \\
\hline Post-operative & $1(2)$ & $4(8)$ \\
\hline \multicolumn{3}{|l|}{ Social level (\%) } \\
\hline Employed & 54 & 72 \\
\hline Retired & 20 & 16 \\
\hline No information & 26 & 12 \\
\hline \multicolumn{3}{|l|}{ Education level (\%) } \\
\hline Illiterate & 42 & 52 \\
\hline Secondary education & 50 & 38 \\
\hline Higher education & 8 & 8 \\
\hline No information & 0 & 2 \\
\hline ICU length of stay (days) median [min-max] & $3[1-22]$ & $8[1-38]$ \\
\hline Hospital length of stay (days) median [min-max] & $14[4-53]$ & $20[3-68]^{*}$ \\
\hline
\end{tabular}

$* p<0.001$ vs. control group. Min: minimum. Max: maximum

The EQ-5D Index of the control group is $0.747 \pm 0.327$ and $0.678 \pm 0.427$ in the sepsis group $(p=0.66)$. The frequency of each level of the EQ-5D of all patients is depicted in Figure 2. The highest rates of level 3 occurred in the dimension usual activities (16\%) and self-care $(10 \%)$ in the sepsis group (S). Table 2 shows the frequency of moderate or severe problems (levels 2 and 3 ) of each level of the EQ-5D for both groups categorized according to age. Older patients ( $>60$ years old) in the sepsis group had a significantly higher prevalence of moderate to severe problems (levels 2 and 3) in all dimensions. However, in younger patients, more moderate or severe problems were seen in the control group than in the sepsis group, particularly in the dimension usual activities ( $57 \%$ vs. $13.3 \%, p<0.01$ ). Overall, patients with sepsis had fewer problems in all five dimensions than patients in the control group. However, older patients (>60 years old) in the sepsis group had a significantly higher prevalence of moderate to severe problems in all dimensions. (Table 2). 
Table 2 - Distribution of EQ-5D values 2 and 3 for the control and sepsis groups according to age categories. São José do Rio Preto, SP, Brazil, 2010

\begin{tabular}{|c|c|c|c|c|c|c|}
\hline Age group & Group & Mobility & Self-care & Usual Activities & Pain/Discomfort & Anxiety/Depression \\
\hline \multirow[t]{2}{*}{$16-39$} & Control & 30.0 & 25.0 & 57.1 & 36.4 & 38.0 \\
\hline & Sepsis & 23.5 & 16.6 & $13.3^{\dagger}$ & 21.7 & 28.6 \\
\hline \multirow[t]{2}{*}{$40-49$} & Control & 30.0 & 50.0 & 28.6 & 22.7 & 28.6 \\
\hline & Sepsis & $11.7^{*}$ & $16.6^{\dagger}$ & 26.7 & 8.7 & $0.0^{\dagger}$ \\
\hline \multirow[t]{2}{*}{$>60$} & Control & 40.0 & 25.0 & 14.3 & 40.9 & 28.6 \\
\hline & Sepsis & $64.7^{*}$ & $66.7^{\dagger}$ & $60.0^{\dagger}$ & $69.5^{*}$ & $71.4^{\dagger}$ \\
\hline
\end{tabular}

Results are shown as percentage (\%).

$* p<0.05$ vs. control group. $+p<0.01$ vs. control group.

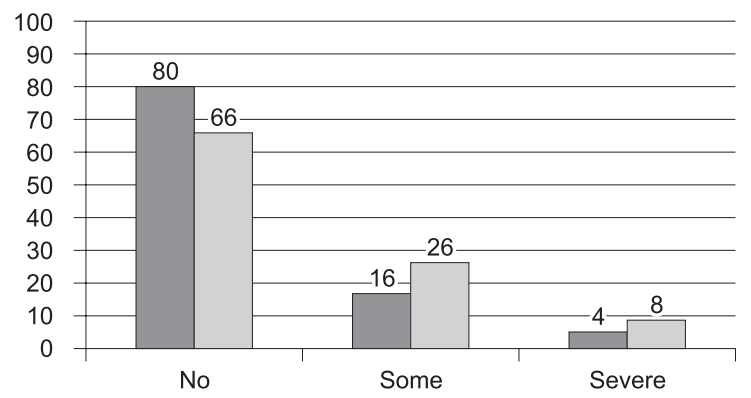

A
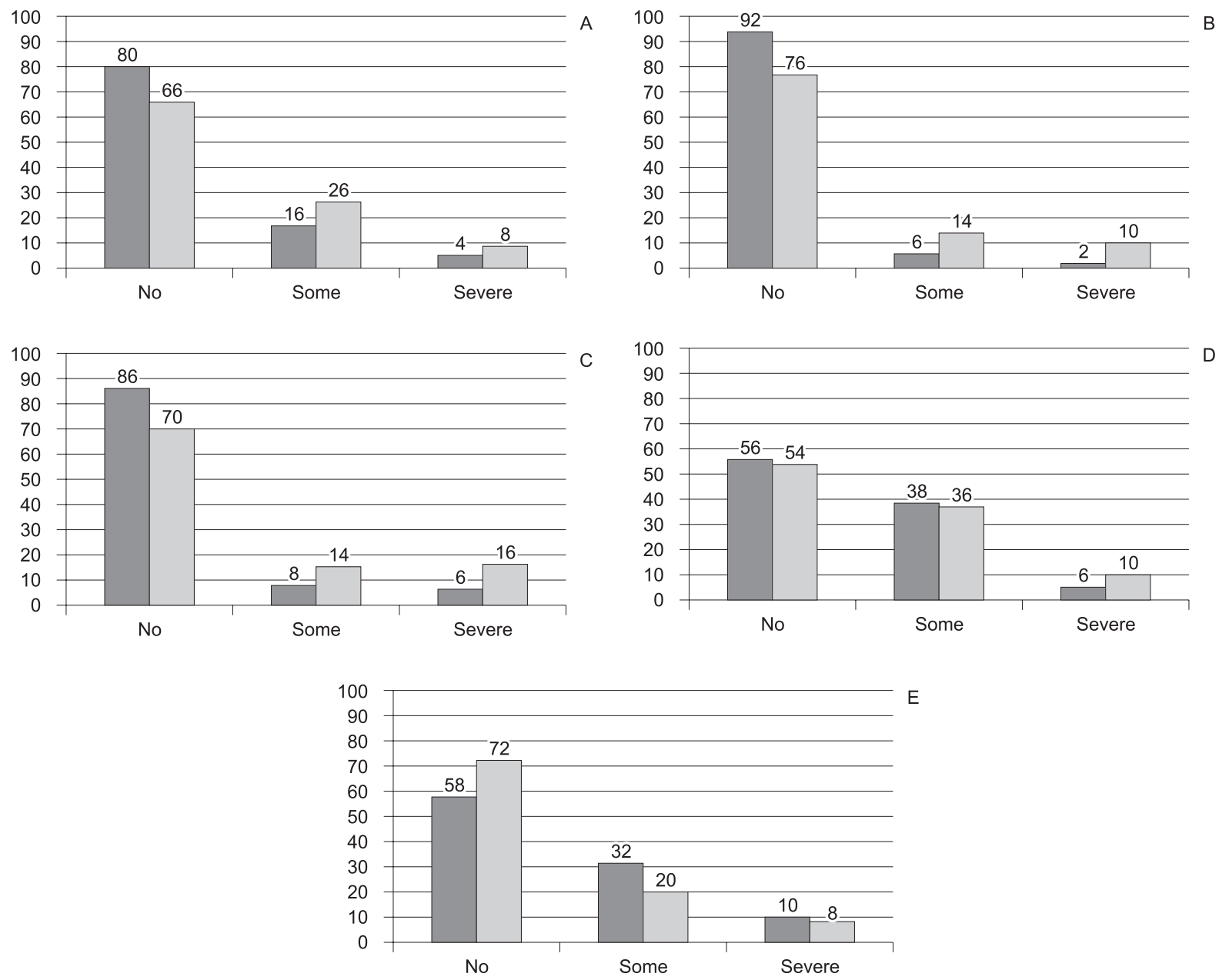

Group control $\square$ Sepsis group

Figure 2 - Frequency (\%) of each level of the EQ-5D (A: mobility; B: self-care; C: Usual activities; D: Pain and discomfort; E: Anxiety and depression). 
There were no differences in EQ-VAS $(72.7 \pm 26.2$, control group; $79.7 \pm 21.1$, sepsis group; $p=0.19$ ) between respondents from both groups (Figure 2 ).

A median value of 60 was obtained for septic patients older than 60 years in comparison to 88 obtained for the patients in the control group $(p=0.09)$ (Table 3 ).

Table 3 - EQ-VAS for the control and sepsis groups according to age categories. São José do Rio Preto, SP, Brazil, 2010

\begin{tabular}{lcc}
\hline \multicolumn{1}{c}{ Age group } & Group $(\mathbf{n})$ & Median [IQ25\%-75\%] \\
\hline $16-39$ & Control (15) & $80.0[80.0-100]$ \\
& Sepsis (18) & $90.0[70.0-100]$ \\
$40-49$ & Control (16) & $82.5[61.2-100]$ \\
& Sepsis (11) & $80.0[7.0-85.0]$ \\
& Control (19) & $88.0[70.0-90.0]$ \\
& Sepsis (21) & $60.0[50.0-90.0]$ \\
\hline
\end{tabular}

\section{Discussion}

Our main results indicate a higher mortality rate for patients with sepsis discharged from the hospital at one year in comparison to critically ill patients without sepsis. We also found a significantly higher prevalence of moderate and severe problems in all quality of life dimensions evaluated for older patients with sepsis.

In our study, the 1-year mortality rate after discharge from ICU was almost two times higher for patients with sepsis (36.5\%) than for critically ill patients without sepsis (19.7\%). The research of magnitude and duration of the effect of sepsis on survival followed up 1505 patients hospitalized with sepsis during 8 years after hospital discharge and only $44 \%$ of the patients with septic shock survived one year after discharge; $30 \%$ of the patients survived after 2 years, and less than $20 \%$ of the patients survived after 8 years $^{(18)}$. Indeed, surgical patients with sepsis had significantly lower 2-year survival than trauma patients (33\% versus $57 \%)^{(19)}$. In a recent published systematic review on long-term mortality and QoL in sepsis, the 1-year mortality after hospital discharged ranged from $7 \%$ to $43 \%$ in seventeen studies including a 1 -year followup. Eight studies compared septic patients to a control non-infected population and found mortality rates from almost 2 to 5 times higher in septic patients ${ }^{(5)}$.

There were no differences in the EQ-5D Index between both groups. However, our results indicate an impact of age in the QoL of septic patients. More than
$60 \%$ of the patients older than 60 years in the sepsis group had either moderate or severe problems in all five dimensions of the EQ-5D, which was significantly higher than in the control group.

Many studies have reported decrements in the patient's Qol scores compared to population norms. Some authors did not find differences in QoL of patients who had sepsis in comparison to critically ill patients without sepsis, but others did.

The QoL of survivors from severe sepsis and septic shock were compared with survivors of critical illness not involving sepsis using EQ-5D(20). They reported that survivors from sepsis and septic shock have a QoL similar to that of survivors from critical illness admitted without sepsis. In surgical patients with sepsis, when compared to trauma patients without sepsis, QoL was reduced to the same level in both groups ${ }^{(19)}$. On the other hand, patients who had sepsis as their primary risk factor for Acute Respiratory Distress Syndrome (ARDS) were compared to ARDS survivors due to trauma, showing that sepsis-induced ARDS determined worse QoL when compared to trauma-induced ARDS. However, it is hard to determine the extent to which the impact on the QoL is attributable to sepsis rather than to $\operatorname{ARDS}^{(21)}$.

Our results suggest an influence of ageing on the quality of life in septic patients. More than $60 \%$ of patients older than 60 years in the sepsis group had either moderate or severe problems in all five dimensions of the EQ-5D, which was significantly higher than in the control group. The severe sepsis in an older population was independently associated with substantial and persistent new cognitive impairment and functional disability among survivors. Survivors' mean age at hospitalization was 76.9 years ${ }^{(6)}$. Other authors demonstrated that elderly patients presented more pain and discomfort and that the worsening in the quality of life was more related to both the cause of ICU admission and the previous low quality of life ${ }^{(22)}$.

Our data show that $24 \%$ to $46 \%$ of the patients in the sepsis group have problems ranging from moderate to extreme regarding the five dimensions, which is in agreement with other study data(19). However, while they reported more problems in the dimensions usual activities and anxiety/depression, we found more problems in the dimension mobility and pain and discomfort. These discrepancies may be due to differences in the population, such as the higher prevalence of surgical patients in our population. In surgical patients with sepsis, almost $60 \%$ had problems in usual activities ${ }^{(19)}$ 
A limitation of this study was the significant number of patients lost to follow up. Proxies account for $50 \%$ of the answers. However, the proxy answers could be reliably used with the EQ-5D when measuring QoL ${ }^{(23)}$. Although controversial, the communication and relationship established between the patient and his/her next of kin can indeed influence the answers(24).

The strength of our study was the adjustment for confounders by comparing the population with sepsis to a nested population of critically ill patients without sepsis.

\section{Conclusion}

After discharge from ICU survivors of sepsis had higher mortality rate than critically ill patients without sepsis. Older patients with sepsis had more moderate and severe problems in all quality of life dimensions evaluated.

In conclusion, longer-term endpoints and QoL should be incorporated in the studies to better understand the effect of interventions and to permit further research, urgently needed in this area. Particularly, efforts should focus on understanding and preventing the functional disability and cognitive impairment losses that accompany sepsis survivors.

\section{References}

1. Martin GS, Mannino DM, Eaton S, Moss M. The epidemiology of sepsis in the United States from 1979 through 2000. N Engl J Med. 2003;348(16):1546-54.

2. Tsiotou AG, Sakorafas GH, Anagnostopoulos G, Bramis

J. Septic shock; current pathogenetic concepts from a clinical perspective. Med Sci Monit. 2005;11(3):RA76-85. 3. American Sepsis Institute [Internet]. Campanha Sobrevivendo à Sepse [acesso em: 20 mar. 2012]. Disponível em: http://www.sepsisnet.org/PDF/ sugestao\%20de\%20ficha\%20de\%20triagem.pdf

4. Sales Jr JA, Lobo SMA, Hatum R, Dias FD, Macedo GL, Costa JI, et al. Sepse Brasil: estudo epidemiológico da sepse em unidades de terapia intensiva brasileiras. Rev Bras Ter Intensiva. 2006;18(1):9-17.

5.Winters BD, Eberlein M, Leung J, Needham DM, Pronovost PJ, Sevransky JE. Long-term mortality and quality of life in sepsis: a systematic review. Crit Care Med. 2010;38(5):1276-83.

6. Iwashyna TJ, Ely EW, Smith DM, Langa KM. Long-term cognitive impairment and functional disability among survivors of severe sepsis. JAMA. 2010;304(16):1787-94.
7. Westphal GA, Vieira KD, Orzechowski R, Kaefer KM, Zaclikevis VR, Mastroeni MF. Análise da qualidade de vida após a alta hospitalar em sobreviventes de sepse grave e choque séptico. Rev Panam Salud Pública 2012;31(6):499-505.

8. Poutsiaka DD, Davidson LE, Kahn KL, Bates DW, Snydman DR, Hibberd PL. Risk factors for death after sepsis in patients immunosuppressed before the onset of sepsis. Scand J Infect Dis. 2009;41(6-7):469-79.

9. Sogayar AMCB, Silva E, Cal RGR, Beer I, Akamine N, Safi J, et al. What are the direct costs of sepsis treatment in Brazilian ICUs? Crit Care 2005;9(Suppl 2):P112.

10. Shorr AF, Micek ST, Jackson WL Jr, Kollef $\mathrm{MH}$. Economic implications of an evidence-based sepsis protocol: can we improve outcomes at lower costs? Crit Care Med. 2007;35(5):1257-62.

11. Hofhuis JG, Spronk PE, van Stel HF, Schrijvers GJ, Rommes JH, Bakker J. The impact of critical illness on perceived health-related quality of life during ICU treatment, hospital stay, and after hospital discharge: a long-term follow-up study. Chest. 2008;133(2):377-85

12. Ferraz MB. Qualidade de vida. Conceito e um breve histórico. Jovem Med. 1998;3:219-222.

13. Fleck MPA. O instrumento de avaliação de qualidade de vida da OMS (WHOQOL - 100): característica e perspectiva. Ciênc Saúde Coletiva 2000;5(1):33-8.

14. Carr AJ, Thompson PW, Kirwan JR. Quality of life measures. Br J Rheumatol. 1996;35(3):275-81.

15. Levy MM, Fink MP, Marshall JC, Abraham E, Angus D, Cook D, et al. 2001 SCCM/ESICM/ACCP/ATS/SIS International Sepsis Definitions Conference. Crit Care Med. 2003;31(4):1250-6.

16. EuroQol - a new facility for the measurement of health-related quality of life. The EuroQol Group. Health Policy. 1990;16(3):199-208.

17. Dolan P. Modeling valuations for EuroQol health states. Med Care. 1997;35(11):1095-108.

18. Kind P, Hardman G, Macran S. UK Population norms for EQ-5D. Discussion Paper 172. York (UK): Centre for Health Economics, University of York; 1999. 98 p.

19.Korosec Jagodic H, Jagodic K, Podbregar M. Longterm outcome and quality of life of patients treated in surgical intensive care: a comparison between sepsis and trauma. Crit Care 2006;10(5):R134.

20. Granja C, Dias C, Costa-Pereira A, Sarmento A. Quality of life of survivors from severe sepsis and septic shock may be similar to that of others who survive critical illness. Crit Care 2004;8(2):R91-8.

21. Davidson TA, Caldwell ES, Curtis JR, Hudson LD, Steinberg KP. Reduced quality of life in survivors of acute 
respiratory dis tress syndrome compared with critically ill control patients. JAMA. 1999;281(4):354-60.

22. Dowdy DW, Eid MP, Sedrakyan A, Mendez-Tellez PA, Pronovost PJ, Herridge MS, et al. Quality of life in adult survivors of critical illness: a systematic review of the literature. Intensive Care Med. 2005;31(5):611-20.

23. Badia X, Díaz-Prieto A, Rué $M$, Patrick DL. Measuring health and health state preferences among critically ill patients. Intensive Care Med. 1996;22(12):1379-84.

24. Roeser K, Eichholz R, Schwerdtle B, Schlarb AA, Kübler $A$. Relationship of sleep quality and health-related quality of life in adolescents according to self- and proxy ratings: a questionnaire survey. Front Psychiatry. 2012;3:76. 